\title{
Pre-service teachers' reflection in reading of literary texts in weblogs
}

\begin{abstract}
This qualitative study examines twenty-five preservice English language teachers' reflective level in their reading of literary texts. 189 weblog entries were analysed. The five levels of reflection identified were Identification, Association, Integration, Analysis, and Transformation, with Identification and Association levels considered a 'surface learning' while the remaining three as 'deep learning'. The results indicated while the percentage of reflection at all levels was almost equally distributed, the combined percentage of the 'deep learning' constituted almost seventy percentage of the total number of weblog entries. This outcome indicated that weblogs were useful for reflection of reading literary texts.
\end{abstract}

Keyword: Reflection; Weblog; Reading; Literary texts 